\title{
Anionic Polymerization of Lactams in Presence of Activating and Alloying Additives
}

\author{
R. Mateva and O. Delev \\ Department of Plastics, Sofia Technological University, \\ $8 \mathrm{Kl}$. Ohridski Blvd., 1756 Sofia, Bulgaria
}

(Received May 20, 1994)

\begin{abstract}
The polymerization of cyclic lactams ( $\varepsilon$-caprolactam and $\omega$-dodecalactam) in the presence of anionic initiator and new activators (modifying additives) was studied. The compounds used as modifying additives have the following structures:
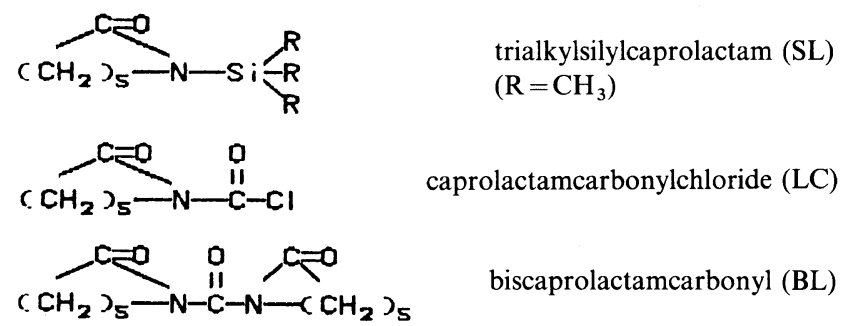

The effects of the activators on the rate of polymerization, conversion, molecular weight, content of olygomer products, thermal stability were established. The polydispersity of the polyamides obtained in the presence of different activators were investigated.

KEY WORDS Lactam / Polymerization $/ \varepsilon$-Caprolactam $/ \omega$-Dodecalactam /
\end{abstract}

A great number of activators for the anionic polymerization of cyclic lactams with various chemical structure have been reported. ${ }^{1-7}$ They are used to overcome the induction period, characteristic of the ionic polymerization of lactams, when imide derivatives accumulate, serving as activators. The aim of the present study was to investigate the effects of new activators. ${ }^{9-11}$

Moreover, it could be expected that, incorporated in the polyamide composition up to reasonable concentration, they would improve some properties such as flame retardancy, thermal and thermooxidative resistance, elasticity etc.

Shalby, Reimshuessel, ${ }^{7}$ and Mateva ${ }^{8}$ have studied the action of $N$-phosphonilated lactams. They found that these compounds are not only very good activators, but contribute to obtain polyamides whose structures differ from those polyamides produced by the conventional anionic activators.

For this reason the studied compounds may be considered not only as activators of the ionic polymerization but also modifiers of polyamides properties.

The main emphasis of the present study was placed on the polymerization of $\varepsilon$-caprolactam $(\varepsilon-\mathrm{CL})$ and $\omega$-dodecalactam ( $\omega$-DL). Because of the specific characteristics of the ring of $\omega$-DL compared with that of $\varepsilon$-CL (different enthalpy $\Delta H$, entropy $\Delta S$, isobaric-isothermal potential $\Delta G$, given in Table I) ${ }^{12}$ it was of great interest to investigate the activating effects of the synthesized compounds ${ }^{10}$ on the polymerization of $\varepsilon$-CL and $\omega$-DL proceeing by anionic mechanism.

Because of the specificity of the polymeriza- 
Table I. Thermodynamic characteristics of 7- and 13-membered lactams ${ }^{12}$

\begin{tabular}{|c|c|c|c|}
\hline \multirow{2}{*}{$\begin{array}{l}\text { Number of } \\
\text { atoms in the } \\
\text { lactam cycle }\end{array}$} & $\Delta H$ & $\Delta S$ & $\Delta G$ \\
\hline & $\mathrm{kcal} \mathrm{mol}^{-1}$ & $\mathrm{kcal} \mathrm{K}^{-1} \mathrm{~mol}^{-1}$ & $\mathrm{kcal} \mathrm{mol}^{-1}$ \\
\hline 7 & -3.3 & 1.1 & -3.6 \\
\hline 13 & -0.7 & 30 & -9.7 \\
\hline
\end{tabular}

tion of the two types of lactams, they will be considered side by side thus showing peculiarities of action of the activators on both monomers. The compounds used as activating additives have the following structures:

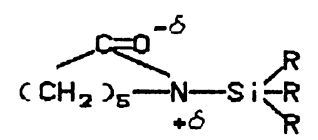

trialkylsilylcaprolactam (SL) $\left(\mathrm{R}=\mathrm{CH}_{3}\right)$

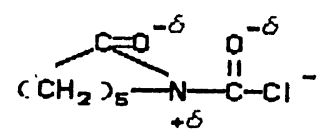

caprolactamcarbonylchloride (LC)

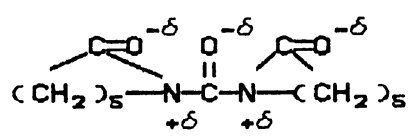

biscaprolactamcarbonyl (BL)

While studying their activating action, a comparison with the most widely used so far activator was done:

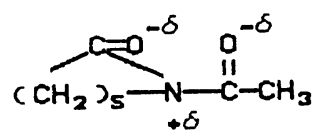

$$
N \text {-acetylcaprolactam (AL) }
$$

The activating effects of the synthesized compounds should depend, first of all, on chemical structure. The substituents at the nitrogen atom of the lactam cycle will polarize the $\mathrm{N}-\mathrm{C}$ bond (the bond will become more labile), because of the rearrangement of the electron density. The labilization of the $\mathrm{N}-\mathrm{C}$ bond is due to an additional partial positive charge $\delta^{+}$at the nitrogen atom. Obviously, higher $\delta^{+}$will cause greater labilization of the $\mathrm{N}-\mathrm{C}$ bond. LC should have the greatest effect, while $\mathrm{AL}$ and $\mathrm{BL}$, the least.

For SL, $\delta^{+}$, is expected to be lowest because of the shifting of $2 \mathrm{~s}^{2}$ electrons from the d-orbital to the Si atom. ${ }^{13}$ The bigger volume of the substituent, $-\mathrm{Si}(\mathrm{R})_{3}$, may cause a decrease of the rate of polymerization. During the inactivated polymerization it is necessary for an $\mathrm{N}$-acyllactam derivative to be formed in order to open the lactam cycle.

The activation effects of the compounds were monitored by decrease of the induction period and acceleration of polymerization as well as decrease of the activating energy of polymerization.

\section{EXPERIMENTAL}

\section{Materials}

As monomers were used: $\varepsilon$-Caprolactam, twice distilled, melting point $68^{\circ} \mathrm{C}$, kept desiccator under inert atmosphere; $\omega$-dodecalactam, twice distilled, melting point $152^{\circ} \mathrm{C}$, kept desiccator under inert atmosphere.

Synthesis of SL: To a solution of $\varepsilon$-caprolactam $(22.6 \mathrm{~g}, 0.2 \mathrm{~mol})$ in $80 \mathrm{ml}$ dichloroethane and triethylamine $(20.2 \mathrm{~g}, 0.2 \mathrm{~mol})$ slowly with continuous stirring and cooling with water, $21.7 \mathrm{~g}(0.2 \mathrm{~mol})$ alkylchlorosilane were added. The temperature of the reaction mixture should not exceed $30^{\circ} \mathrm{C}$. The reaction was run for about $2 \mathrm{~h}$, precipitated triethylamine hydrochloride was filtered out, dichloroethane evaporated and the raw product (yield 92\%) was distilled under vacuum.

Synthesis of LC: A tree-neck flask, supplied with a separating funnel and an outlet to the absorber of phosgene, was loaded with $100 \mathrm{ml}$ dry dichloroethane containing $10.5 \mathrm{~g}$ phosgene. After energetic stirring for $5 \mathrm{~min}, 40 \mathrm{ml}$ dichloroethane in which were dissolved $18.5 \mathrm{~g}(0.1$ mol) SL were added. The reaction proceeded for $90 \mathrm{~min}$ at $(5-10)^{\circ} \mathrm{C}$, the temperature was raised to $20^{\circ} \mathrm{C}$ at the end of the process. The reaction mixture was distilled under vacuum in 
order to remove excess phosgen and solvent. The final product was purified by recrystallization and vacuum distillation.

Synthesis of BL: In a tree-neck flask, equivalent amounts of SL and LC were mixed. The reaction was run for $4 \mathrm{~h}$ at $20^{\circ} \mathrm{C}$ on continuous stirring. The obtained phosgene and alkylchlorosilane were removed by vacuum distillation. The solution was concentrated to half of its original volume and the white crystals were filtered out and rinsed with hexane. Then the raw material was recrystallized. The compounds obtained were characterized by IR-and ${ }^{1} \mathrm{H}$ NMR-spectroscopy.

In the IR-spectra of the compounds the following bands were present: at $1640 \mathrm{~cm}^{-1}$ for the amide carbonyl group, stretching vibrations at $1250 \mathrm{~cm}^{-1}$ and $860 \mathrm{~cm}^{-1}$ for $\mathrm{Si}-\mathrm{C}$ (alkyl groups, bound to $\mathrm{Si}$ ) for $\mathrm{SL}$; at $1790 \mathrm{~cm}^{-1}$ characteristic of $-\mathrm{COCl}$ (for $\mathrm{LC}$ ). There is no maximum for $\mathrm{NH}$ of an amide group.

${ }^{1} \mathrm{H}$ NMR-spectra were recorded in $\mathrm{DSCl}$ on a JEOL JMMPS-100. $100 \mathrm{MHz}$ spectrometer using as the internal standard, 1\% HMDSO. The following were observed: multiplet at $\delta=1.6 \mathrm{ppm}$ for the protons of the middle methylene groups of the lactam ring; triplet at $\delta=2.3 \mathrm{ppm}$ for the protons of the methylene group next to $\mathrm{CO}$; triplet at $\delta=3.2 \mathrm{ppm}$ for the protons of the methylene group next to $\mathrm{N}$ (for LC it is at $\delta=3.8 \mathrm{ppm}$ ). There was no signal for the proton of the amide group at $\delta=7.8 \mathrm{ppm}$.

\section{Methods}

The anionic polymerization of $\varepsilon$-caprolactam was carried out in block at $180^{\circ} \mathrm{C}$. $1 \mathrm{~mol} \%$ $\mathrm{Na}$-caprolactamate was used to initiate the process (L).

The degree of conversion was determined after extraction with dry chloroform for $8 \mathrm{~h}$ in a Soxhlet apparatus and drying of the polymer at $60^{\circ} \mathrm{C}$ in a vacuum drier to avoid hydrolysis of $\mathrm{N}-\mathrm{C}$ bonds.

GPC investigation of the low molecular fraction (monomers, dimers, and trimers) was carried out on a Waters apparatus under the following conditions: columns Ultrastyragel $500+500+100 \AA$, eluent tetrahydrofuran (THF), flow rate $0.8 \mathrm{ml} \mathrm{min}{ }^{-1}$, temperature $45^{\circ} \mathrm{C}$ and a polystyrene standard was used.

The constants of chain transfer were determined according to ${ }^{14}$ the equation:

$$
\overline{D P}^{-1}=\frac{[\mathrm{C}] \text { "live" }}{2 \cdot \alpha \cdot[\mathrm{M}]}+\frac{K_{\mathrm{tr}}}{K_{\mathrm{p}}+K_{\mathrm{tr}}}
$$

where:

$[\mathrm{C}]$ "live"- the concentration of "live" ends;

$$
\frac{K_{\mathrm{tr}}}{K_{\mathrm{p}}+K_{\mathrm{tr}}}=K_{\mathrm{tr}}^{\prime} \text { the constant of transfer; }
$$

$\alpha=$ yield $\% / 100$ degree of conversion;

$\overline{D P}=\bar{M} / M_{\mathrm{o}}$ degree of polymerization;

$M_{\mathrm{o}}$, molecular weight of the monomer: 197 for $\omega$-DL and 113 for $\varepsilon-C L$.

$\bar{M}$ was the average absolute molecular weight of the polyamide, obtained by GPC measurements of the high molecular fraction on a Waters apparatus under the following conditions: columns, Ultrastyragel $10^{6}+10^{5}+$ $10^{4}+10^{3}+500 \AA$, eluents 1,2,4-trichlorobenzene and 4,4'-thio-bis(6-m-butyl-3-cresol) at $1.0 \mathrm{~g} /$ per gallon, flow rate, $1.0 \mathrm{ml} \mathrm{min}^{-1}$, temperature, $145^{\circ} \mathrm{C}$ and a polyethylene standard was used.

Concentrated $\mathrm{H}_{2} \mathrm{SO}_{4}$ was used as the solvent for determination of the average viscosimetric molecular weight $M_{\mathrm{v}} . K$ and $\alpha$ in the MarkHouwink equation are $K=9.10^{-3}, \alpha=0.53$ for polydodecalactam and $K=4.30^{-3}, \alpha=0.7$ for polycaprolactam, respectively. ${ }^{15}$

Thermogravimetric investigation was carried out on a Perkin-Elmer apparatus within the temperature range $(50-500)^{\circ} \mathrm{C}$ at a heating rate $10 \mathrm{deg} \mathrm{min}^{-1}$ in an inert atmosphere.

Chain branching of the polymer was determined as $g^{\prime}=[\eta] /\left[\eta_{\mathrm{e}}\right]$, where: $[\eta],\left[\mathrm{dl} \mathrm{g}^{-1}\right]$ is the characteristic viscosity calculated based on $M_{\mathrm{v}} ;\left[\eta_{\mathrm{e}}\right],\left[\mathrm{dlg}^{-1}\right]$ is the characteristic vis- 
cosity determined by light scattering according to ref. 16.

\section{RESULTS AND DISCUSSION}

The activating effects of the synthesized compounds SL, LC, and BL on the polymerization of $\varepsilon-C L$ and $\omega$-DL can be evaluated by following the kinetics of polymerization of the monomers in the presence the above compounds and criteria given in the Introduction.

The activators lower the induction period of both monomers. The curves of conversion
(Figure 1 and Figure 1a) for the three types of activators are characteristic of the activating polymerization and differ substantially from the those of typical S-like unactivated polymerization.

The influence of $\mathrm{LC}, \mathrm{BL}$, and $\mathrm{SL}$ on the induction period as well as on rate of polymerization, i.e., conversion curves, may be explained by the formation of $N$-lactam centers as follows:

Initiation and growth of the polymer chain in the presence of:

1. SL

Initiation

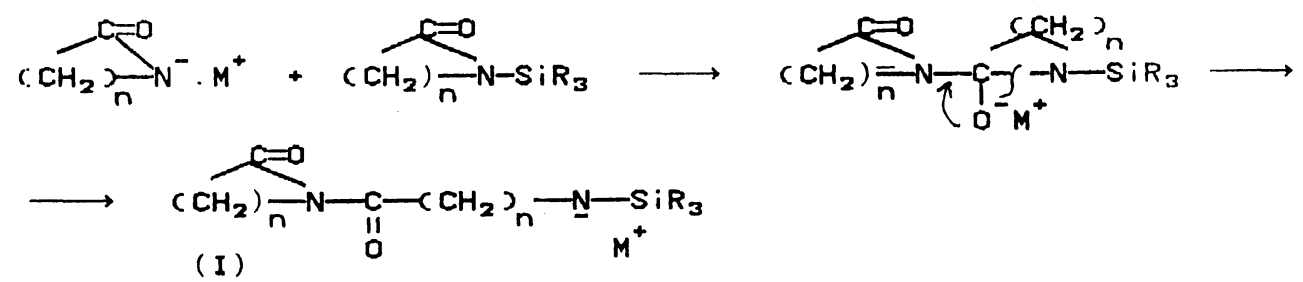

Initiation in the presence of small amounts of SL

(.I)
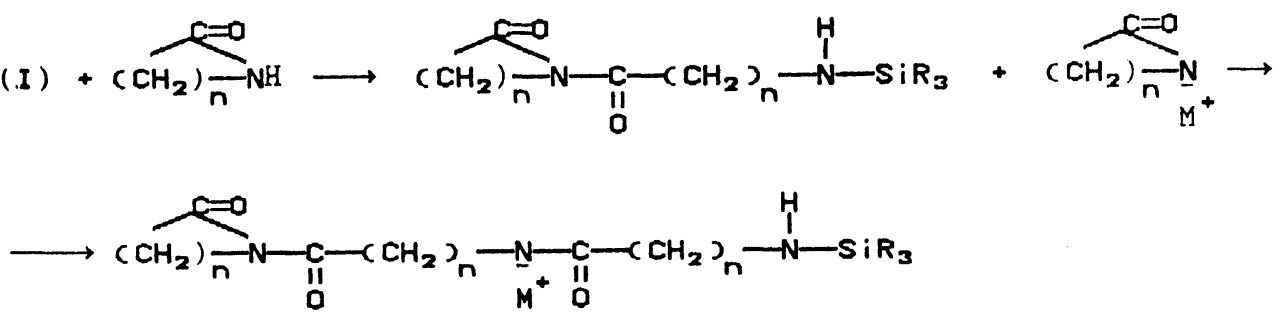

Initiation in the presence of large amounts of SL
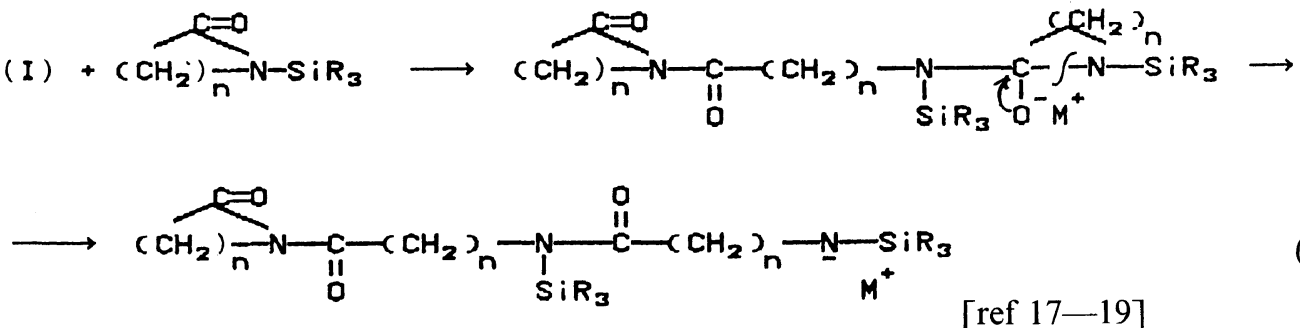

[ref 17-19]

The IR-spectrum provides evidence for the incorporation of the sililated lactam into the macromolecule. Stretching vibrations at 890 ,
755 , and $690 \mathrm{~cm}^{-1}$ are characteristic of the $\mathrm{Si}-\mathrm{C}$ cond, while the those at $750-785 \mathrm{~cm}^{-1}$ indicate the presence of $\mathrm{N}-\mathrm{Si}$ bonds. 
2. Initiation and growth in the presence of $\mathrm{LC}$

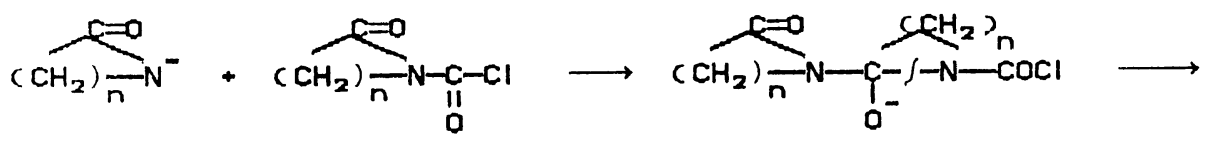

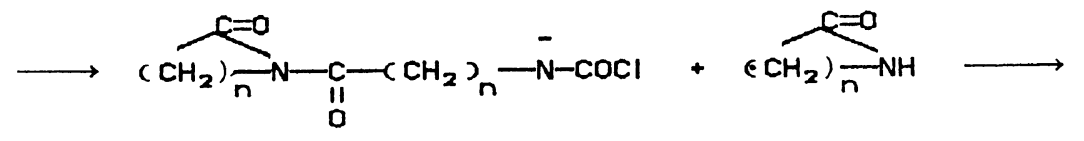

$$
\begin{aligned}
& \longrightarrow\left(\mathrm{CH}_{2}\right) \frac{-\mathrm{N}}{\mathrm{N}}-\underset{\substack{11 \\
0}}{\mathrm{C}}-\left(\mathrm{CH}_{2}{ }_{n}-\mathrm{NH}-\mathrm{COCl}+\underset{\left(\mathrm{CH}_{2}\right) \frac{\mathrm{C}}{\mathrm{n}}=\mathrm{N}}{-} \longrightarrow\right.
\end{aligned}
$$

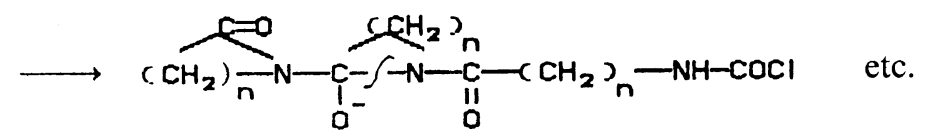

Possibility for nascent formation of $\mathrm{BL}$

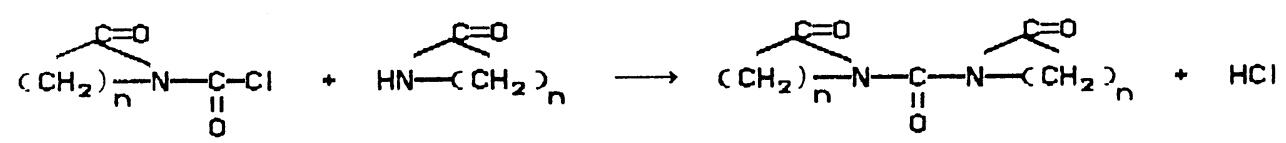

After which SL reacts according to the mechanism below. The released $\mathrm{HCl}$ may take part in chain interruption

$$
\longrightarrow \mathrm{N}^{-} \longrightarrow \mathrm{HCl} \rightleftarrows-\mathrm{NH}^{-}
$$

and react with a molecule of caprolactam forming a salt

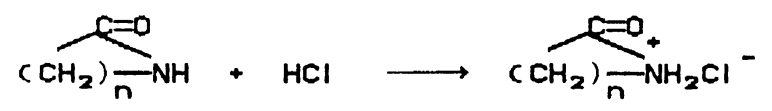

or a lactam anion

$$
\left(\mathrm{CH}_{2}\right) \frac{\mathrm{C}=\mathrm{N}}{\mathrm{n}}+\mathrm{HCl} \longrightarrow\left(\mathrm{CH}_{2}\right) \frac{\mathrm{C}=\mathrm{O}}{\mathrm{n}} \mathrm{NH}+\mathrm{Cl}^{-}
$$

Most probably, the high $K_{\mathrm{p}}$ is due to reaction $2 \mathrm{e}$.

3. Initiation of polymerization and chain growth in the presence of $\mathrm{BL}$

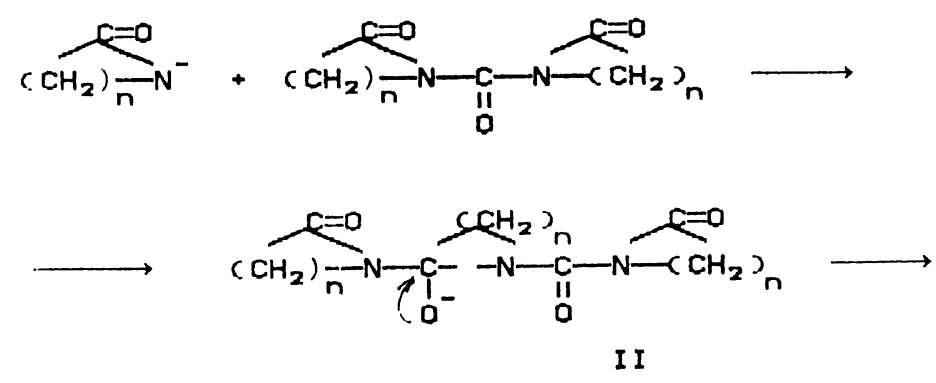



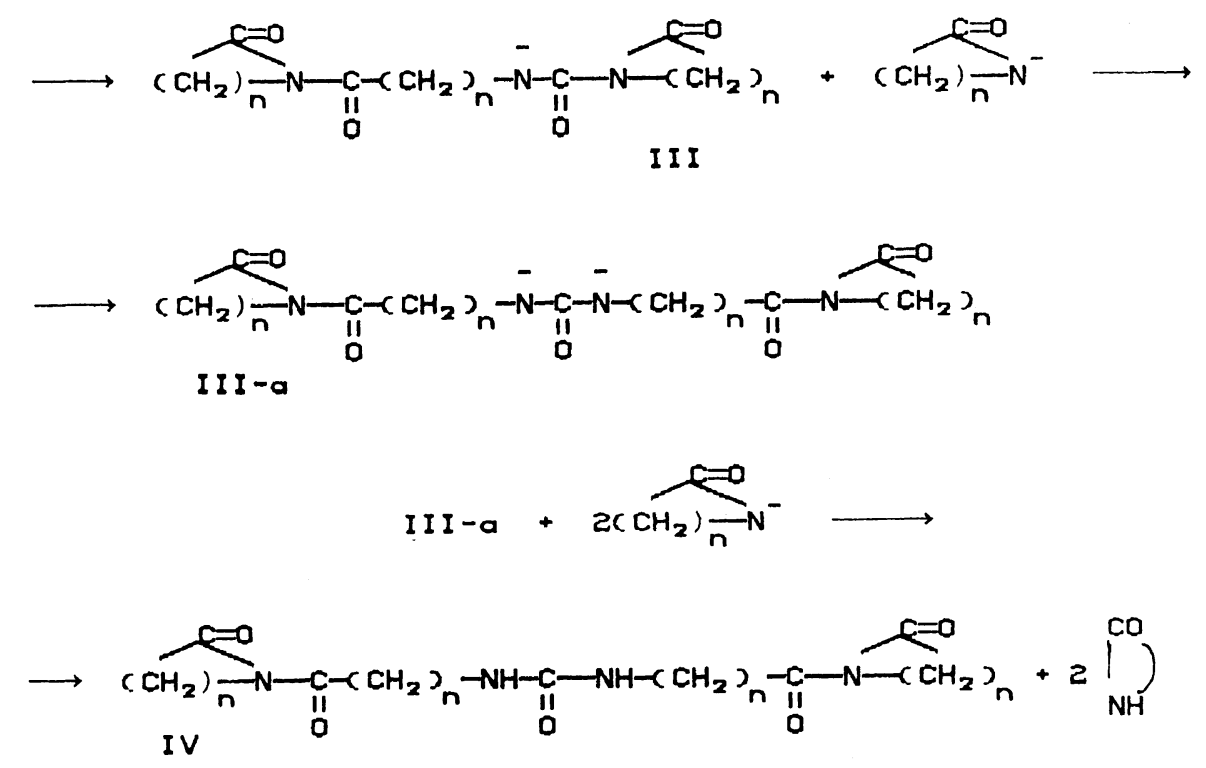

Table IIa. Induction period $\left(t_{\text {ind }}\right)$, maximum rate of conversion $\left(W_{\max }\right)$, maximum degree of conversion $(\alpha)$, average viscosimetric molecular wight $\left(\bar{M}_{\mathrm{v}}\right)$ and degree of polymerization $(\overline{D P})$ of PA- 6 obtained in the presence of different activators

\begin{tabular}{|c|c|c|c|c|c|c|}
\hline \multirow{2}{*}{ No. } & \multirow{2}{*}{ Activator } & \multirow{2}{*}{$\frac{\Gamma_{\text {ind }}}{\min }$} & \multirow{2}{*}{$\frac{W_{\max }}{\% \min ^{-1}}$} & \multirow{2}{*}{$\frac{M_{\mathrm{v}}}{\mathrm{g} / \mathrm{g} \mathrm{mol}}$} & \multirow{2}{*}{$\alpha$} & \multirow{2}{*}{$\begin{array}{c}D P \\
-\end{array}$} \\
\hline & & & & & & \\
\hline 1 & - & 30 & 1.0 & 14000 & 0.43 & 124 \\
\hline 2 & $\mathrm{AL}$ & 0.5 & 4.8 & 35400 & 0.95 & 313 \\
\hline 3 & SL & 6.5 & 1.8 & 38500 & 0.96 & 340 \\
\hline 4 & $\mathrm{LC}$ & 0.5 & 3.5 & 34000 & 0.92 & 300 \\
\hline
\end{tabular}

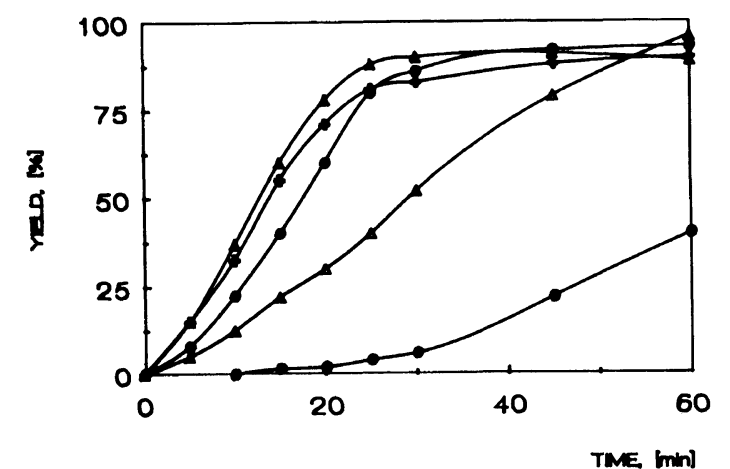

Figure 1a. Conversion of $\varepsilon$-caprolactam during anionic polymerization in the presence of different activators. Temperature of polymerization $180^{\circ} \mathrm{C} ;[\mathrm{L}]=1 \mathrm{~mol} \%$; $[\mathrm{A}]=\mathrm{mol} \%$. - - , without activator; $-\mathbf{\Delta}-$, activator $\mathrm{AL} ;-\triangle-$, activator $\mathrm{SL} ;-\mathrm{O}-$, activator $\mathrm{BL} ;-\times-$, activator LC.
The macromonomer IV may have two-center growth with lactamate anions by reactions of $1 \mathrm{c}$ and $2 \mathrm{f}$. The rate of the polymerization of $\varepsilon$-CL using the three activating additives $\mathrm{AL}$, $\mathrm{BL}$, and $\mathrm{LC}$ is of the same order. As seen in Figure 1a and Table IIa, the activating effect of SL is considerable. The rate of polymerization is about twice the unactivated one.

The conversion curves of $\omega$-DL not differ substantially from those of $\varepsilon$-CL. More significant are the differences in $W_{\max }$ and $\tau_{\text {ind }}$ (Figure $1 \mathrm{~b}$ and Table IIb). The rates of polymerization of $\omega$-DL in the presence of AL, LC, and SL are approximately the same.

The polymerization of $\varepsilon-C L$ and $\omega$-DL showed that $\bar{M}$ is highest for SL and BL, and 
Table IIb. Induction period $\left(t_{\text {ind }}\right)$, maximum rate of conversion $\left(W_{\max }\right)$, average viscosimetric molcular weight $\left(\bar{M}_{\mathrm{v}}\right)$ and yields

\begin{tabular}{|c|c|c|c|c|c|}
\hline \multirow{2}{*}{ No. } & \multirow{2}{*}{ Activator } & \multirow{2}{*}{$\frac{\tau_{\text {ind }}}{\min }$} & \multirow{2}{*}{$\frac{W_{\max }}{\% \min ^{-1}}$} & \multirow{2}{*}{$\frac{\text { Yield }}{\%}$} & \multirow{2}{*}{$\frac{\bar{M}_{\mathrm{v}}}{\mathrm{g} / \mathrm{g} \mathrm{mol}}$} \\
\hline & & & & & \\
\hline 1 & - & 20.0 & 10.0 & 72 & 35000 \\
\hline 2 & $\mathrm{AL}$ & 0.5 & 15.0 & 97 & 70000 \\
\hline 3 & SL & 2.0 & 15.0 & 95 & 85000 \\
\hline 4 & BL & 3.5 & 12.5 & 93 & 92000 \\
\hline 5 & $\mathrm{LC}$ & 0.5 & 15.0 & 96 & 61000 \\
\hline
\end{tabular}

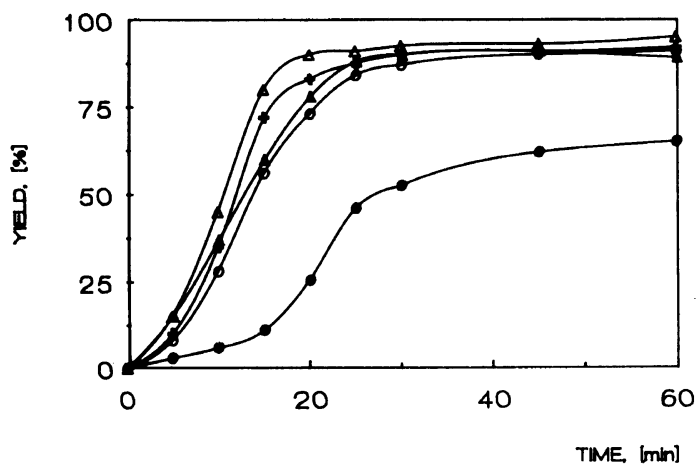

Figure 1b. Conversion of $\omega$-dodecalactam during anionic polymerization in the presence of different activators. Temperature of polymerization $220^{\circ} \mathrm{C} ;[\mathrm{L}]=1 \mathrm{~mol} \%$; $[\mathrm{A}]=1 \mathrm{~mol} \%$. - - - , without activator; $-\mathbf{\Delta}-$, activator $\mathrm{AL} ;-\triangle-$, activator $\mathrm{SL} ;-\mathrm{O}-$, activator $\mathrm{BL}$; $-\times-$, activator LC.

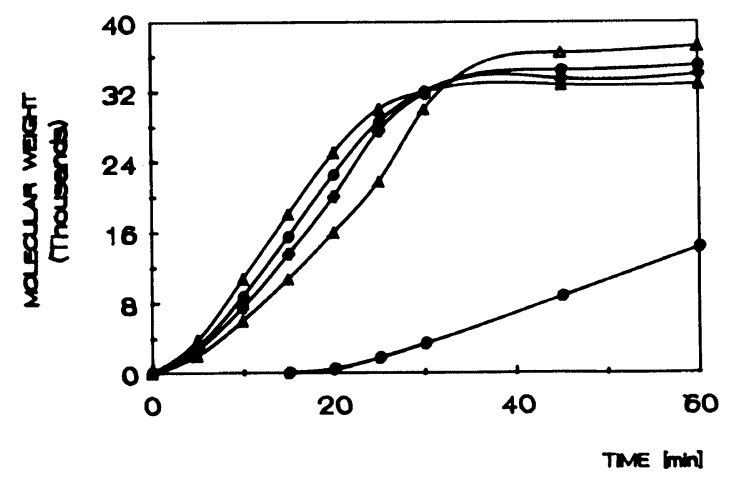

Figure 2a. Viscosimetric molecular weight of PA-6, obtained in the presence of different activators. Temperature of polymerization $180^{\circ} \mathrm{C} ;[\mathrm{L}]=1 \mathrm{~mol} \%$; [A] $=$ $1 \mathrm{~mol} \%$; [A] $=1 \mathrm{~mol} \%$. - - - , without activator; - $\mathbf{A}$ activator $\mathrm{AL} ;-\triangle-$, activator $\mathrm{SL} ;-\mathrm{O}-$, activator $\mathrm{BL}$; $-x-$ activator $\mathrm{LC}$.

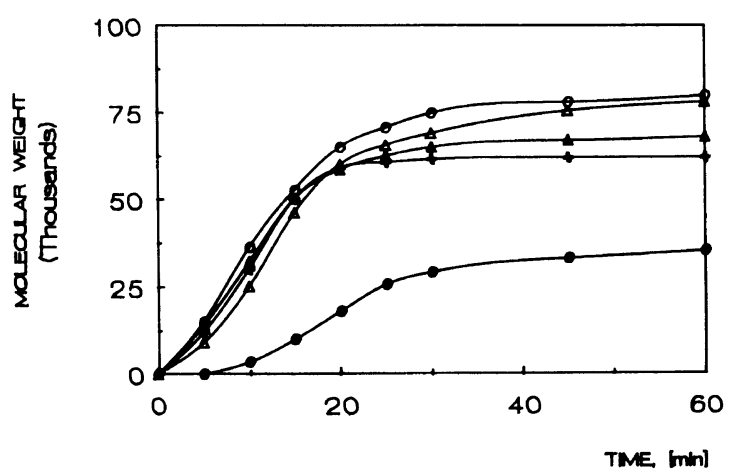

Figure 2b. Viscosimetric molecular weight of obtained PA-12 in the presence of different activators. Temperature of polymerization $220^{\circ} \mathrm{C} ;[\mathrm{L}]=1 \mathrm{~mol} \%$; $[\mathrm{A}]=1 \mathrm{~mol} \%$. - - without activator; $-\mathbf{\Delta}-$, activator $\mathrm{AL} ;-\triangle-$, activator $\mathrm{SL} ;-\mathrm{O}-$, activator $\mathrm{BL} ;-\times-$, activator $\mathrm{LC}$.

only for LC, it is lower than that for AL (Tables IIa and IIb).

The effects of the investigated compounds on (DP), the molecular weight of the polymer obtained, were apparent. $\bar{M}$ increases with the time of polymerization. The dependence of $\overline{D P}$ on the degree of conversion $(\alpha), \overrightarrow{D P}=f(\alpha)$, in eq 1 can be used to assess the characterize polymerzation. For both monomers it is proportional (Figures $3 a$ and $3 b$ ) which means that the polymerization can be assumed "pseudo living". This also shows that polymerization occurs with chain transfer. The degree of conversion $(\alpha)$ is highest for SL, while for the inactivated process, least (Tables IIa and IIb).

Besides chain transfer of the monomer and reaction 2.d, other side processes are possible 


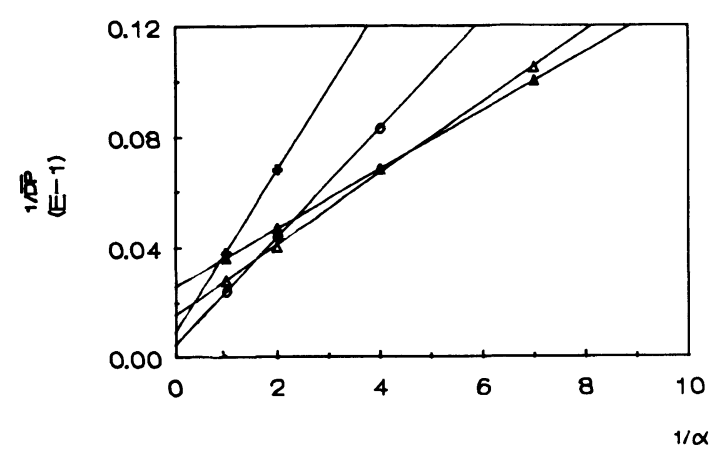

Figure 3a. Dependence of $\overline{D P}^{-1}=f\left(\alpha^{-1}\right)$ for obtained $\mathrm{N}-6$ in the presence of different activators. Temperature of polymerization $180^{\circ} \mathrm{C} ;[\mathrm{L}]=1 \mathrm{~mol} \%$; $[\mathrm{A}]=1 \mathrm{~mol} \%$. $-\times-$, activator $\mathrm{LC} ;-\mathbf{\Delta}-$, activator $\mathrm{AL} ;-\triangle-$, activator $\mathrm{SL} ;-\mathrm{O}-$, activator $\mathrm{BL}$.

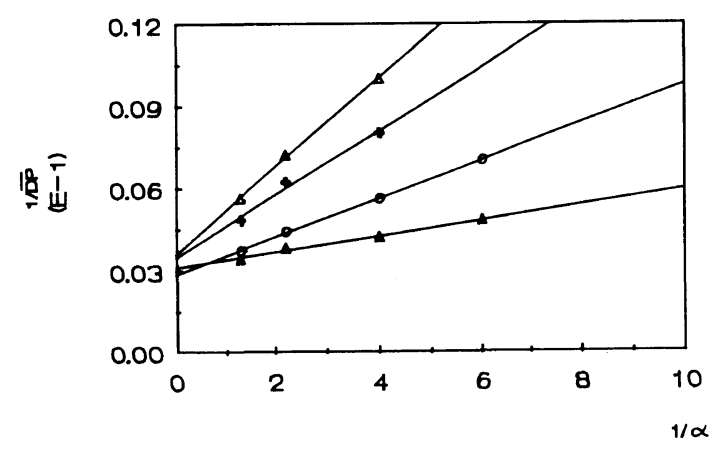

Figure 3b. Dependence of $\overline{D P}^{-1}=\mathrm{f}\left(\alpha^{-1}\right)$ for obtained $\mathrm{N}-12$ in the presence of different activators. Temperature of polymerization $220^{\circ} \mathrm{C}$; [L] $=1 \mathrm{~mol} \%$; [A] $=1 \mathrm{~mol} \%$. $-\times-$, activator $\mathrm{LC} ;-\Delta-$, activator $\mathrm{AL} ;-\triangle-$, activator $\mathrm{SL} ;-\mathrm{O}-$, activator $\mathrm{BL}$.

leading to treasfer and interruption of the chain as evident by the degree of branching of the macromolecules.

These proceses occur when $K_{\mathrm{tr}}^{\prime}$ is higher. The calculated values of chain transfer $K_{\mathrm{tr}}^{\prime}$ (Table IIIa and IIIb) show that constants of transfer for the additives SL and LC are considerably higher. It is evident that during the polymerization of both monomers, LC causes the highest chain transfer followed by AL, BL, and SL.

It is natural to be supposed that activators take part in the polymerization as carriers of active centers.

GPC data show that the degree of poly-
Table IIIa. Constant of chain transfer $\left(K_{\mathrm{tr}}^{\prime}\right)$ and concentration of alive ends ([C] "live") during the polymerization of $\varepsilon$-CL in the presence of different activators

\begin{tabular}{cccc}
\hline No. & Activator & $K^{\prime} \times 10^{-}$ & {$[\mathrm{C}]_{\text {live }}$} \\
\hline 1 & AL & 0.9 & 1.04 \\
2 & SL & 0.77 & 1.3 \\
3 & LC & 1.0 & 2.8 \\
4 & BL & 0.8 & 1.8 \\
\hline
\end{tabular}

Table IIIb. Constant of chain transfer $\left(K_{\mathrm{tr}}^{\prime}\right)$ and concentration of the alive ends ([C] "live") during the polymerization of $\omega$-DL in the presence of different activators

\begin{tabular}{cccc}
\hline No. & Activator & $K_{\mathrm{tr}}^{\prime} \times 10^{-3}$ & {$[\mathrm{C}]_{\text {"live" }}$} \\
\hline 1 & AL & 3.1 & 0.3 \\
2 & SL & 2.8 & 1.55 \\
3 & LC & 3.3 & 1.15 \\
4 & BL & 2.9 & 0.68 \\
\hline
\end{tabular}

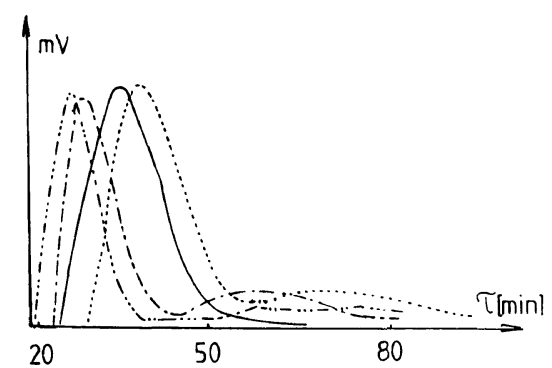

Figure 4. Polydispersity of samples of obtained N-6 in the presence of different activators. Temperature of polymerization $180^{\circ} \mathrm{C} ;[\mathrm{L}]=1 \mathrm{~mol} \%$; $[\mathrm{A}]=1 \mathrm{~mol} \% .-\cdot-\cdot$, activator $\mathrm{LC} ; \cdots \cdots$, activator $\mathrm{AL} ;-$, activator $\mathrm{SL} ;-\cdots-$, activator $\mathrm{BL}$.

dispersity is influenced by the chemical nature of the activators (Figure 4). The lowest and highest degrees of polydispersity were achieved by the use of SL and LC respectively.

Most probably, $-\mathrm{SIR}_{3}$ of the chain is transferred to unsubstituted lactam or to $\mathrm{H}$-arom of an amide group of the polyamide chain, thus regenerating SL. This has been proven for $\mathrm{AL}^{13}$ according to the reaction: 


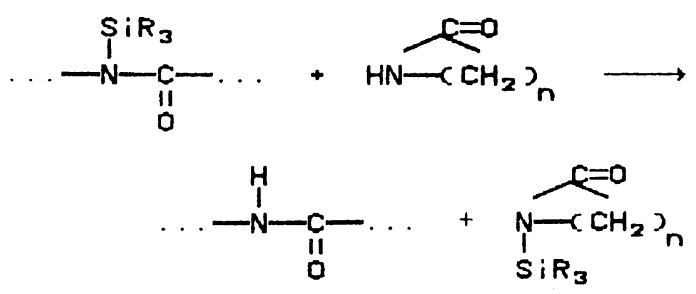

In this way, redistribution of $-\mathrm{SiR}_{\mathbf{3}}$ residues along the polymer chain takes place.

Reactions of cross-linking due to the following interactions with LC may occur during polymerization:

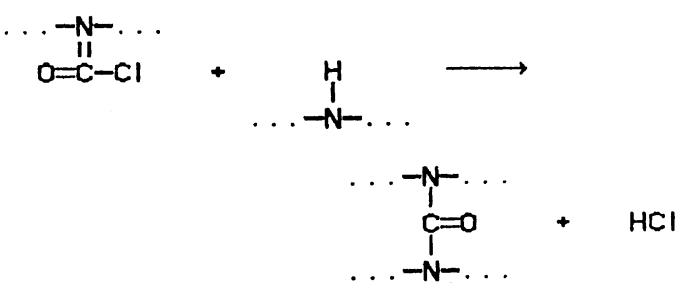

In the following is discussed the possibility of forming crosslinked chains, i.e., gelfraction as a result of condensation between the obtained $^{20)}$ is shown by Puffer et al. ${ }^{21)} \beta$-diketones of the type $-\mathrm{CO}-\mathrm{CH}_{2}-\mathrm{CO}-\mathrm{NH}-\mathrm{SiR}_{3}{ }^{5}$ (and their enol form) and neighboring chains possessing labilazed $\mathrm{H}$-aroms. This is the case of SL due to it strongly labilazed $\alpha$-proton near the sililated repeated amide group:
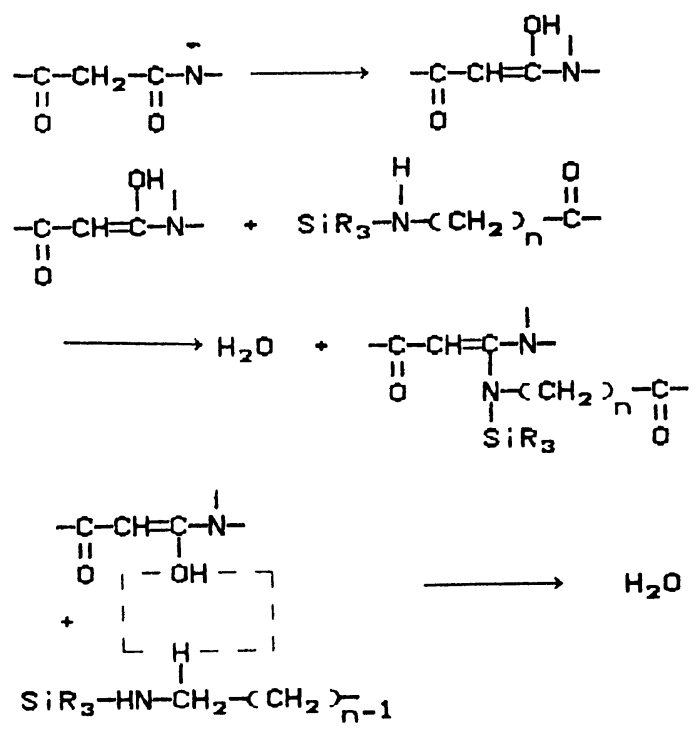

$\mathrm{H}_{2} \mathrm{O}$

Polym. J., Vol. 27, No. 5, 1995

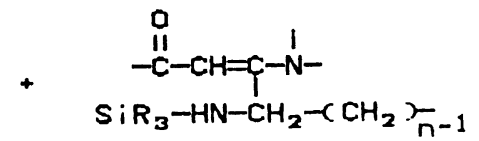

This reaction explaines the large gelfraction in the case of considerable SL.

To follow the process of polymerization, exhaustion of the monomer with time was monitored. The formation of oligomer products (dimers and trimers) as well as their behaviour during polymerization were investigated too.

GPC investigation of the low molecular fractions showed that in the first minutes of polymerization, low molecular dimers and trimers with SL (Figure 5) and only dimers with BL (Figure 6) were present. In both cases tetramers were not formed. The maximum concentration of dimers (Figure 7) and trimers (Figure 8) in the low molecular fraction was achieved 30 minutes from the beginning of polymerization. The curves prove that some low molecular dimers and trimers interact both with the growing polymer chain or directly with the active monomer center, and are used up completely with time. This begins 30 th minutes after starting the polymerization, i.e., shortly before the equilibrium $\mathrm{P}_{n} \rightleftarrows \mathrm{P}_{n-1}+\mathrm{M}$ of the polymerization or limited degree of conver-

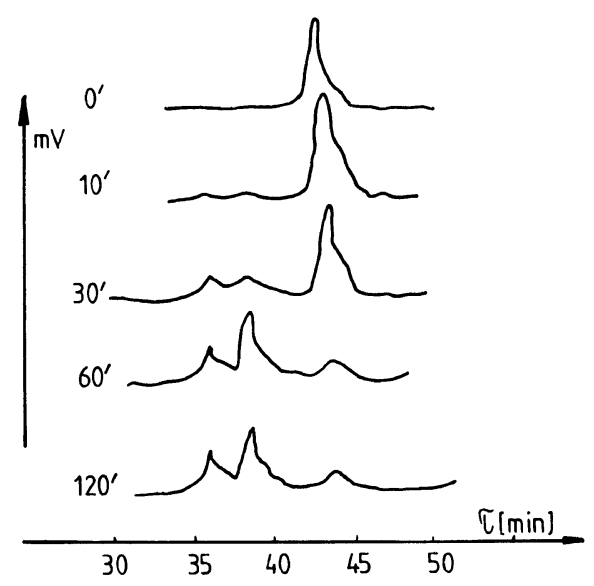

Figure 5. Change in the composition of the low molecular fraction during polymerization of $\omega$-dodecalactam in the presence of SL as activator. Temperature of polymerization $220^{\circ} \mathrm{C}$; [L $]=1 \mathrm{~mol} \%$; $[\mathrm{A}]=1 \mathrm{~mol} \%$. 


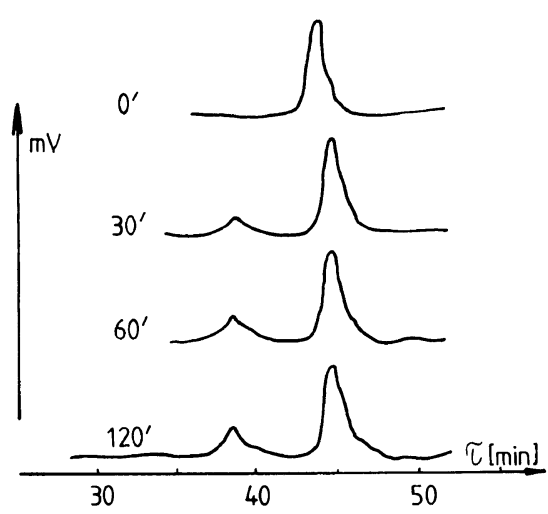

Figure 6. Change in the composition of the low molecular fraction during polymerization of $\omega$-dodecalactam in the presence of BL as activator. Temperature of polymerization $220^{\circ} \mathrm{C}$; [L] $=1 \mathrm{~mol} \%$; $[\mathrm{A}]=1 \mathrm{~mol} \%$.

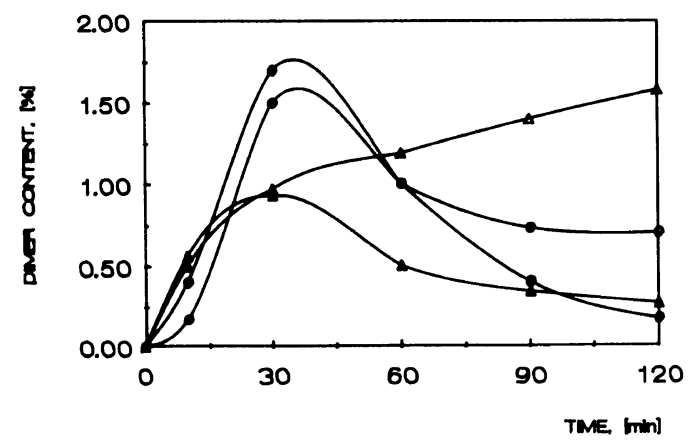

Figure 7. Change in the content of dimers in the low molecular fraction of PA-12, obtained in the presence of different activators. Temperature of polymerixation $220 \mathrm{C}$; $[\mathrm{L}]=1 \mathrm{~mol} \%$. - - - without activator; - $\mathbf{-}-$, activator $\mathrm{AL} ;-\triangle-$, activator $\mathrm{SL} ;-\mathrm{O}-$, activator $\mathrm{BL}$.

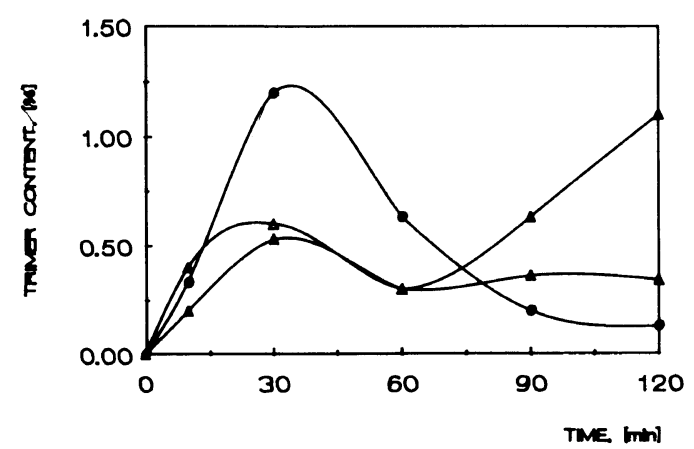

Figure 8. Change in trimers content in the low molecular fraction of PA-12 obtained in the presence of different activators. Temperature of polymerization $220^{\circ} \mathrm{C}$; [L]= $1 \mathrm{~mol} \%$. - - , without activator; - $-\boldsymbol{\Lambda}-$, activator AL; $-\triangle-$, activator SL. sion. Moreover, the oligomer products during inactivated polymerization and those obtained when $\mathrm{BL}$ is used as the activator, and exausted completely compared to the case when AL is used (Figures 7 and 8). The behaviour of the dimers and trimers is different when the activator is SL. They do not show exhaustion. Small increases in concentration with the time is observed. The participation of the activators in reactions of chain transfer should exert effect on the structure of the polyamides obtained. Activators with high $K_{\mathrm{tr}}^{\prime}$ should provide branched polymers when higher quantities are applied, especially in cases when the active center is transferred to the polymer chain. This is also confirmed by investigation on the branching of macromolecules according to. ${ }^{16}$ The data for samples of PA- 6 obtained in the presence of different activators in quantity $5 \mathrm{~mol} \%$ are given in Table IV. According to the constants of branching " $g$ " the activators follow the same order as constants of chain transfer $K_{\mathrm{tr}}^{\prime}$.

The effects of activators on the acceleration of polymerization and shortening (in the most

Table IV. Branching $\left(g^{\prime}\right)$ of PA-6 obtained in the presence of different activating additives

\begin{tabular}{|c|c|c|c|c|}
\hline \multirow{2}{*}{ No. } & \multirow{2}{*}{ Activator } & {$[\eta]$} & {$[\eta]_{\mathrm{e}}$} & $g^{\prime}=[\eta] /[\eta]_{e}$ \\
\hline & & $\mathrm{dlg}^{-1}$ & $\mathrm{dlg}^{-1}$ & {$[-]$} \\
\hline 1 & $\mathrm{AL}$ & 1.61 & 2.02 & 0.80 \\
\hline 2 & SL & 1.59 & 2.02 & 0.79 \\
\hline 3 & $\mathrm{LC}$ & 2.39 & 3.89 & 0.61 \\
\hline 4 & $\mathrm{BL}$ & 1.49 & 2.00 & 0.74 \\
\hline
\end{tabular}

Table V. Activation energy $\left(E_{\mathrm{a}}\right)$ of PA-6 obtained in the presence of different activating additives

\begin{tabular}{|c|c|c|c|c|}
\hline \multirow{2}{*}{ No. } & \multirow{2}{*}{ Activator } & \multirow{2}{*}{$\frac{\text { Content }}{\operatorname{mol} \%}$} & \multirow{2}{*}{$\frac{A \times 10^{-}}{\mathrm{mol} \mathrm{mol}^{-1} \mathrm{~s}^{-1}}$} & \multirow{2}{*}{$\frac{E_{\mathrm{a}}}{\mathrm{kcal} \mathrm{mol}^{-1}}$} \\
\hline & & & & \\
\hline 1 &.- & -- & 0.919 & 18.9 \\
\hline 2 & $\mathrm{AL}$ & 1 & 0.468 & 13.2 \\
\hline 3 & SL & 1 & 0.632 & 15.3 \\
\hline 4 & LC & 1 & 0.481 & 13.8 \\
\hline 5 & BL & 1 & 0.579 & 14.5 \\
\hline
\end{tabular}


cases elimination) of the induction period are due to the considerable decrease of activating energy $E_{\mathrm{a}}$. It should be expected that the decreace of $E_{\mathrm{a}}$ by various activators will result in increased rate of polymerization and shortening the induction period (Table V).

$E_{\mathrm{a}}$ can be explained by the effects of the rearrangement of the electron density in the molecules of the activator, which determines

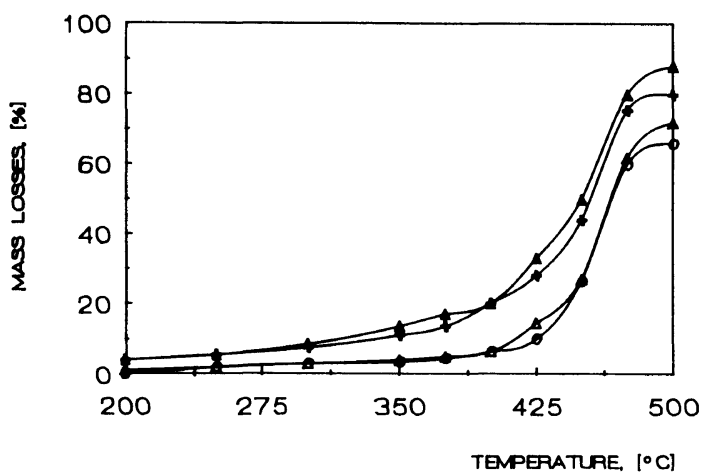

Figure 9a. Mass loss on heating PA-6 obtained in the presence of different activators. Temperature of polymerization $180^{\circ} \mathrm{C} ;[\mathrm{L}]=1 \mathrm{~mol} \% ;[\mathrm{A}]=1 \mathrm{~mol} \%$. - $\times-$, activator $\mathrm{LC} ;-\mathbf{\Delta}-$, activator $\mathrm{AL} ;-\triangle-$, activator $\mathrm{SL}$; $-\mathrm{O}$-, activator $\mathrm{BL}$. the stability of the ring and its opening by the action of the anionic initiator.

The incorporation of activators into the polymer chains would also exert effect on the thermal behaviour of the polyamides. Investigation of the thermal stability of PA- 6 showed that $E_{\mathrm{a}}$ is the highest when $\mathrm{BL}$ and $\mathrm{SL}$ are used (Figure 9a). The biggest mass loss at heating was observed for samples obtained in the

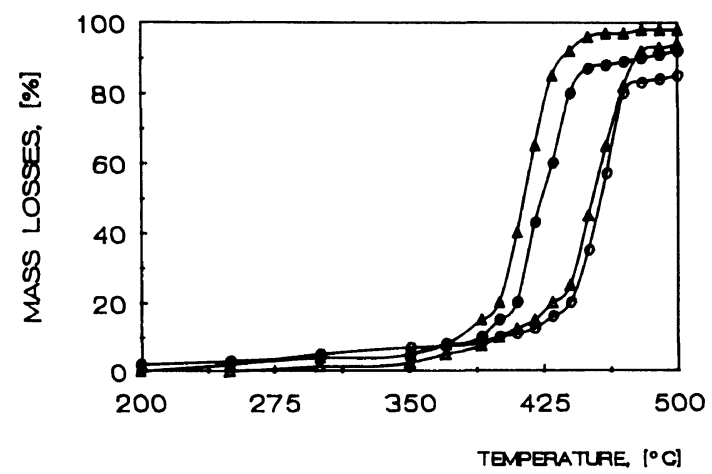

Figure 9b. Mass loss on heating PA-12 obtained in the presence of different activators. Temperature of polymerization $220^{\circ} \mathrm{C} ;[\mathrm{L}]=1 \mathrm{~mol} \%$; $[\mathrm{A}]=1 \mathrm{~mol} \%$. - $-\times-$, activator $\mathrm{LC} ;-\boldsymbol{\Delta}-$, activator $\mathrm{AL} ;-\triangle-$, activator $\mathrm{SL}$; $-\mathrm{O}-$, activator BL.

Table VIa. Thermal index of destruction for $5 \%$ (T-5\%) and $50 \%$ (T-50\%) mass loss, rate of destruction $\left(W_{\text {destr. }}\right)$ at $200-300^{\circ} \mathrm{C}$ and maximum rate of destruction for PA- 6 obtained in the presence of different activators

\begin{tabular}{|c|c|c|c|c|c|}
\hline \multirow{2}{*}{ No. } & \multirow{2}{*}{ Activator } & \multirow{2}{*}{$\frac{\mathrm{T}-5 \%}{{ }^{\circ} \mathrm{C}}$} & \multirow{2}{*}{$\frac{\mathrm{T}-50 \%}{{ }^{\circ} \mathrm{C}}$} & \multicolumn{2}{|c|}{$W_{\text {destr. }} / \% \min ^{-1}$} \\
\hline & & & & $(200-300)^{\circ} \mathrm{C}$ & $\max$ \\
\hline 1 & $\mathrm{AL}$ & 250 & 460 & 0.5 & 21.5 \\
\hline 2 & SL & 390 & 450 & 0.1 & 16.5 \\
\hline 3 & LC & 250 & 452 & 0.27 & 24 \\
\hline 4 & BL & 410 & 465 & 0.03 & 15 \\
\hline
\end{tabular}

Table VIb. Thermal index of destruction for $5 \%$ (T-5\%) and $50 \%$ (T-50\%) mass loss, mass loss at $200^{\circ} \mathrm{C}\left(\mathrm{ML}-200^{\circ} \mathrm{C}\right)$ and $300^{\circ} \mathrm{C}\left(\mathrm{ML}-300^{\circ} \mathrm{C}\right)$, rate of destruction $\left(W_{\text {destr }}\right)$ at $200-300^{\circ} \mathrm{C}$ and maximum rate of destruction for PA- 6 obtained in the presence of different activators

\begin{tabular}{|c|c|c|c|c|c|c|c|}
\hline \multirow{2}{*}{ No. } & \multirow{2}{*}{ Activator } & \multirow{2}{*}{$\frac{\mathrm{T}-5 \%}{{ }^{\circ} \mathrm{C}}$} & \multirow{2}{*}{$\frac{\mathrm{T}-50 \%}{{ }^{\circ} \mathrm{C}}$} & \multirow{2}{*}{$\frac{\text { ML-200C }}{\%}$} & \multirow{2}{*}{$\frac{\text { ML-300C }}{\%}$} & \multicolumn{2}{|c|}{$W_{\text {destr }} / \% \min ^{-1}$} \\
\hline & & & & & & $(200-300)^{\circ} \mathrm{C}$ & $\max$ \\
\hline 1 & - & 360 & 410 & 0.5 & 4 & 0.4 & 25 \\
\hline 2 & $\mathrm{AL}$ & 323 & 400 & 0.5 & 4 & 0.4 & 28 \\
\hline 3 & SL & 375 & 454 & 0.5 & 2 & 0.2 & 16 \\
\hline 4 & $\mathrm{BL}$ & 300 & 460 & 0.5 & 5 & 0.5 & 18 \\
\hline
\end{tabular}


presence of $\mathrm{AL}$ and $\mathrm{LC}$. It is seen from the thermal indices of destruction in the range $200-300^{\circ} \mathrm{C}$ that the highest value is for $\mathrm{AL}$, while the lowest, for activator BL (Table VIa). The considerable stabilizing role of $\mathrm{BL}$ is due to the stable lactam ring at the end of the chain. ${ }^{22}$ Investigation on the thermal destruction of PA-12 (Figure 9b and Table VIb) showed that the polymers obtained in the presence of SL possess the lowest degrees and rates of destruction in the range $200-300^{\circ} \mathrm{C}$, while the highest, for $\mathrm{AL}$ in the case of inactivated anionic polymerization. The maximum rate of destruction was observed above $390-400^{\circ} \mathrm{C}$ and in general changed in the same order as the rate of destruction at $200-300^{\circ} \mathrm{C}$.

The formation of copolymer of caprolactam and SL is evident by the data obtained after taking the IR-spectrum of the product formed when caprolactam and SL reacted in the ratio $1: 1$. The absorption bands at $1325 \mathrm{~cm}^{-1}$ and $900 \mathrm{~cm}^{-1}$ are characteristic for $\mathrm{Si}-\mathrm{C}$ bonds while that at $790 \mathrm{~cm}^{-1}$ indicates the presence of $\mathrm{Si}-\mathrm{N}$ bonds. The spectrum demonstrates that the concentration of NH-groups decreases as seen from the peak centered at $5.6 \mathrm{ppm}$.

\section{CONCLUSIONS}

1. The compounds synthesized using $N$ acyllactams proved to be good activators of the lactam polymerization, due to rearrangement of the electrons in the molecules and labilization of $\mathrm{N}-\mathrm{C}$ bonds as a result of polarization.

2. The compounds above decrease the activation energy of polymerization, eliminate the induction period and significantly increase the rate of polymerization as well as degree of conversion. The activators compared with AL, show lower polydispersity of polymers obtained (lowest for SL) as well as on branching (highest, for BL) although the activation energy and degree of convertion are of the same order. It is suggested that $\mathrm{BL}$ reacts as a bifunctional compound only during the polymerization of
$\psi$-DL.

3. The compounds incorporated into polyamides improved considerably thermal stability (in case of SL).

\section{REFERENCES}

1. R. Scelia, J. Appl. Polym. Sci., 8, 1363 (1964).

2. Courtanids Ltd-C31A5E, Manufacture of Nylon 6, GB Patent, 1136392 (1968).

3. M. A. Ei-Azmirly, V. V. Korshak, V. A. Sergeev, and Z. F. Saicina, Vysokomol. Soedin., Ser. A, 9, 944 (1967).

4. R. A. Cimini and D. C. Sundberg, Polym. Eng. Sci., 26, 560 (1986).

5. J. Stehlicek, K. Gehrke, and J. Sebenda, Collect. Czech. Chem. Commun., 32, 370 (1967).

6. J. Brozek. M. Marek, J. Roda, and J. Kralicek, Makromol. Chem., 189, 17 (1988).

7. S. W. Salaby and H. K. Reimschuessel, J. Polym. Sci., Polym. Chem. Ed., 15, 1349 (1977).

8. R. Mateva and N. Dencheva, J. Polym. Sci., Polym. Chem. Ed., 30, 1449 (1992).

9. R. Mateva and O. Delev, Synthesis of N-Substituted Lactams, Bulg. Patent, 79, 425 (1987).

10. R. Mateva and O. Delev, Activators for Anionic Polymerization of Lactams, Bulg. Patent, 79, 424 (1987).

11. R. Mateva and O. Delev, Copolyamids of Cyclic Lactams, Bulg. Patent, 87, 681 (1988).

12. A. K. Bonezkaja and S. M. Skuratov, Vysokomol. Soedin., Ser. A, 1, 532 (1969).

13. J. Roberts and M. Caserio, "Basic Principles of Organic Chemistry", "Mir", Moskba, 1978, (russion), part II, p. 591.

14. D. Pepper, Eur. Polym., 1, 41 (1965).

15. S. L. Ivanova, S. Kulichichin, O. Alkaeva, N. Akumuschkin, J. Virskii, and A. Magin, Vysokomol. Soedin., Ser. A, 20, 2813-2815 (1978).

16. Z. Tuzar, J. Kondelikova, J. Kraliček, K. Sandova, M. Strohalnikova, and V. Kubanek, Angew. Makrom. Chem., 64, 123 (1977).

17. E. Colvin, "Silicon Organic Synthesis," Butterworths, London, 1981, Chapter 4, p 4-19.

18. H. Chao and J. Policastro, J. Polym. Sci., Polym. Lett., 24, 253 (1986).

19. V. Bazant, V. Chalovsky, and J. Rathovsky, "Silikony", Mir, Moskba, 1960, p 94.

20. D. Ivanoy, "Organic Chemistry", Nauka i Iskustvo, Sofia, 1957, p. 180.

21. R. Ruffer, J. Stehlicek, and J. Shebenda, Macromol. Chem., Macromol. Symp., 219 (1992).

22. R. Mateva, M. Ivanova, and V. Kabaivanov, Compt. Rend. Acad. Bulg. Sci., 39 (6), 47 (1986). 